\title{
OPTIMIZING THE CONTROL AND AUTOMATION OF VARIABLE TORQUE ON 3-PHASE INDUCTION MOTOR USING PROGRAMABLE NEURO LOGIC CONTROLLER AND VARIABLE FREQUENCY DRIVE
}

\author{
J. N. Eneh ${ }^{1, *}$ and P. C. Ene ${ }^{2}$ \\ 1, Department of EleCtronic EngineERING, University of Nigeria, NSUKKA, ENUGu STATE, NIGERIA \\ 2, DePARTMENT OF ELECTRICAL/ELECTRONIC ENGINEERING, ENUGU STATE UNIVERSITY OF SCIENCE AND \\ TECHNOLOGY, ENUGU, ENUGU STATE, NIGERIA \\ Email addresses: ${ }^{1}$ nnenna.eneh@unn.edu.ng, ${ }^{2}$ eneh.princewill@esut.edu.ng
}

\begin{abstract}
This paper presents optimizing the control and automation of variable torque on 3-phase induction motor using programmable neuro logic controller (PNLC) and variable frequency drive (VFD). The system was designed by developing a transfer model of the nonlinear input current from the load cells and feed to an improved PLC model for an approximate current function which is identified by the VFD with respect to the controlled load torque to power the $4.07 \mathrm{KW}$ rated 3-phase induction motor. The models were implemented using control system toolbox, neural network toolbox and simulated with Simulink in MATLAB. From the simulation of the improved controller model, the step response time performance of the PLC was improved from 2.25s to $1.22 \mathrm{~s}$ with the PNLC.The simulation result of the VFD controlled 3-PIM motor shows that $37.07 \%$ of energy (power) was conserved compared to a characterized system with $20 \%$ energy conservation rate.
\end{abstract}

Keywords: 4.07KW 3-phase induction motor, PLC, ANN, VFD, Energy conservation rate

\section{INTRODUCTION}

Industrial technical production process involves the creation of goods and services (products) for the satisfaction of human wants; among these products includes consumable goods which man depends on daily for survival. However the ever increasing population of man, their inevitable desire for food, outdated industrial production equipment and high cost of energy has made it difficult for manufacturing companies to meet up with the increasing demand and supply of consumable products. In the past, manufacturing companies simply maximizes production by employing more variable factors 0 production like labor, machines, etc; however this is very much cost effective in terms of finance and energy consumption rate.

Overtime, system upgrade have beenidentified as a better conversion process to economically optimize production performance in industries, because of its low cost, efficiency and limited time of implementation [1]. To achieve this upgrade, the use of electric drives and intelligent control systems (controllers), were proposed by [1]. The electric drive mechanism is divided into two major categories which are the alternating current $(A C)$ motor and the direct current (DC) motor. However [2-4] suggested that AC motors (induction motor to be specific) are better for industrial applications than the DC type, because of its rugged nature, easy installation, adaptability, controllability, self start and ability to generate higher torque.

Today the 3-phase induction motor (3-PIM) iscommonly employed for major industrial applications due to its ability to self start unlike the single phase types. The most common industrial applications includes punching presses, shears, hoists, cranes, elevators, fans, centrifugal pump, most machinery tools, wood working tools, compressors, crushers, reciprocating pumps among others. Despite the wide application range and merit attributes associated with 3-PIM, they have certain limitations such as nonlinear speed characteristics. By default, 3-PIM is designed to operate at constant speed, but in certain

${ }^{*}$ Corresponding author, tel: +234 - $806-481-1235$ 
manufacturing process where variable torque is inevitable like a crusher system with variable load conveyors. It is certain that this variable load will produce a nonlinear transfer function that will affect the speed of the induction motor, and hence there is need for speed control.

Various methodologies have been proposed for the speed control of 3-PIM, employing techniques like the armature control method [2], flux control method, pulse width modulation control technique [6] among others, however in situation where large amount of variable torque drives the motor; these aforementioned techniques cannot be fully relied upon. This is because some of the control techniques like armature and pulse width modulation control methods induces current and voltage harmonics as noise into the 3-PIM, flux control method induces vibration [13] and above all, none of these control method conserve energy. In other word, the conventional control process lacks automation.

Recently, the use of microcontroller, arduino controller, programmable logic controllers (PLC) have all been called upon to addressed these nonlinear challenges $[3,8]$ but however despite their vast industrial applications, it does not mean they are the best or that they produce the best control response. Studies $[8,9]$ and industrial experience revealed that one of the most employed controller which is the, PLC sometimes gets aggressive, poor response time to nonlinearity, overshoot and most importantly does not solve the problem of energy conservation, other controllers mentioned equally shares the same fate, and as a result the main challenge of manufacturing industries today is the need for an improved controlled system.

According to [12], more than $95 \%$ of industrial controllers are of the PLC type, however due to their inability to fully combat uncertainties, produce optimal control performance and high cost of installing a new controller entirely; hence there is need to improve the existing controller design. An improved design PLC controller will ensure that nonlinearity is eliminated from the controlled signal and enable the 3-PIM to operate at a constant speed and steady state. However this is acceptable when the motor operates at maximum load, but makes no sense if the same speed is used at a reduced load, because at this point energy is wasted.If the same speed is used for variable loads processing, large amount of energy will be wasted through the process and life span of the industrial system will be reduced. Not mentioning high cost of energy not utilized or recycled. Therefore, there is need for an automated industrial control process to ensure longevity of the industrial systems and at the same time conserve useful energy and reduced cost of maintenance.

\section{THE PROPOSED SYSTEM}

The proposed system is designed using a programmable logic neuro controller (PLNC), load sensors, 3-PIM, variable frequency drive (VFD) power supply system and the crusher as shown in figure 1. The controller is used to improve the control performance of the nonlinear transfer function from the input load sensor. This controlled signal (current with it equivalent torque) were supplied by the VFD and used to control the plant with respect to the load. The power supply was fed from a three phase power $415 \mathrm{~V}$ transformer according to the 3-PIM specifications. With this system, it is expected that the operational speed and power consumed by the plant will be based on the signal current supplied from the input load cell, therefore ensuring that a complete controlled response is achieved and energy conserved.

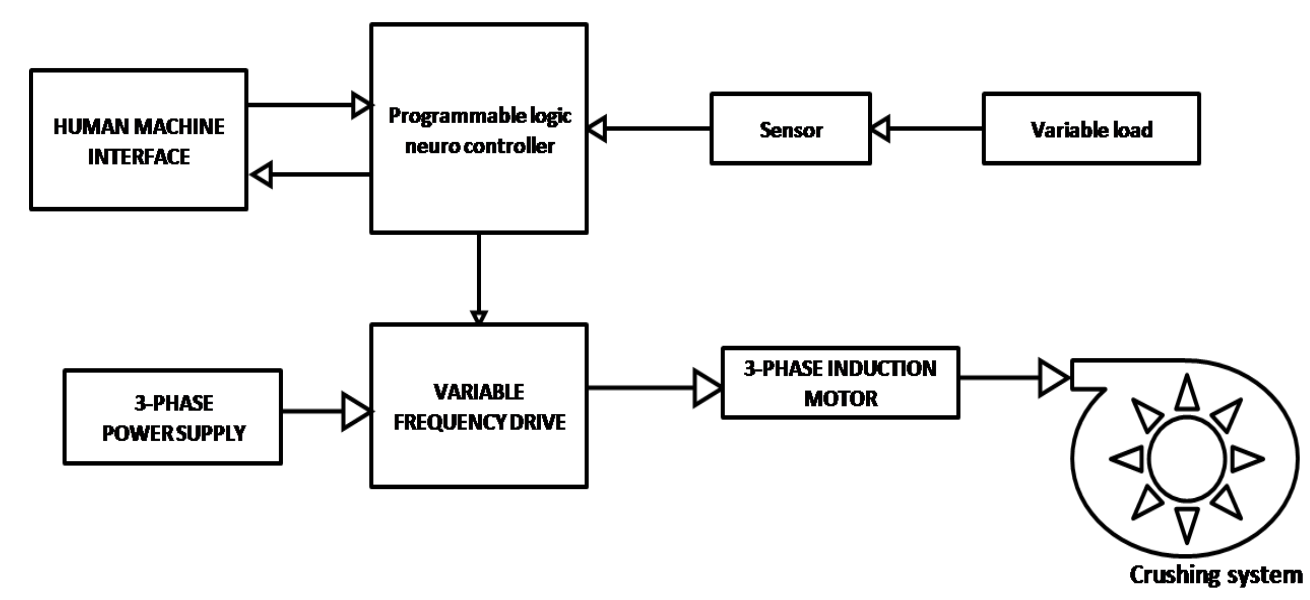

Figure 1: the proposed system block diagram 


\subsection{System Design Method}

The proposed system was designed using process model and work flow charts. The process model was achieved by developing a transfer function model of the nonlinear signal from the load. The signal is feed to the PLC model and then identified by as a nonlinear auto regressive model of the ANN, and trained using back propagation algorithm. This training process produced the desired programmable neuro logic controller (PNLC) model, which will serve as a reference model for the control of other input signals. The controlled signal is feed to the VFD model to control and automate the 3-PIM.

\subsection{Transfer function model}

The transfer function is identified as a discrete time series separated by over one seconds as time delay. The transfer function is employed to define the relationship between the inputs signals (current) generated from the sensor (load cells) and varying coefficient. The instantaneous transfer function is defined as;

$$
Y(s)=\frac{b_{o}+b_{1 s}+\cdots \cdot b_{N} s^{N}}{1+a_{1 s}+\cdots \cdot a_{N} s^{N}}
$$

Where $\mathrm{N}$ represents the number of poles specified with the transfer function order parameter. The varying coefficients from the various input current is presents as $a 1, \ldots$, aN and varying coefficient for the output current is $b_{0}, b_{1}, \ldots, b N$ to the corresponding input ports, $\mathrm{S}$ is the discrete time, $\mathrm{s}^{\mathrm{N}}$ is the output (speed, power).

\subsection{Model of the PLC}

The PLC is developed using transfer function model which relates the varying coefficient of the sensor time series Laplace, with a step response of the PLC through a feedback process. This is presented using the simulink model below; while the process was monitored by the HMI using the simulation parameters in Table 2.

Table 1: PLC and 3-PIM Simulation Parameters

\begin{tabular}{ll}
\hline Parameters & Specification \\
\hline 3-PIM & LGPT -02DN(F)/415V \\
Noise Level & Max 45Db \\
Damper Area & $0.5 \mathrm{~m}^{2}$ \\
Running Time and Max & $0-10(\mathrm{~s}) ; 5252(\mathrm{rpm})$ \\
speed & AC, 415V; $50 / 60 \mathrm{~Hz}$ \\
Power Supply & $10 \mathrm{AWG}$ \\
Wire Size & $2 / 3$ point \\
Control Signal & $6 \mathrm{~kg}$ \\
Weight & $4.07 \mathrm{Kw}$ \\
Ratings & $1.1 \mathrm{Amp}$ \\
Current & $0 \sim 90^{\circ}\left(\mathrm{Max} 93^{\circ}\right)$ \\
Angle of Rotation & L/R switch \\
Rotate Direction & $3(1.5)$ Amp 415V \\
Auxiliary Switch Rating & $>70000 \mathrm{cycles}$ \\
Life Cycle & Specification \\
PLC & 20 input, 12 outputs \\
Number of I/O & $60 \mathrm{~W}$ \\
Power consumption & $24 \mathrm{~V}$ DC, 15 A for \\
Power supply inrush & $20 \mathrm{~ms}$ \\
current & $24 \mathrm{VDC}$ \\
Power supply &
\end{tabular}

The model of the PLC controller (see figure 2) was simulated and the result shows that the PLC did not address the nonlinearity on time with a delay of 2.41 sec. also overshoot was experienced showing that the PLC did not achieve settling and steady state on time. Also, during the period of oscillation as shown on the HMI (see figure 3), the system experienced variation in the amplitude thereby introducing nonlinearity to the current. Hence there is need for improvement.

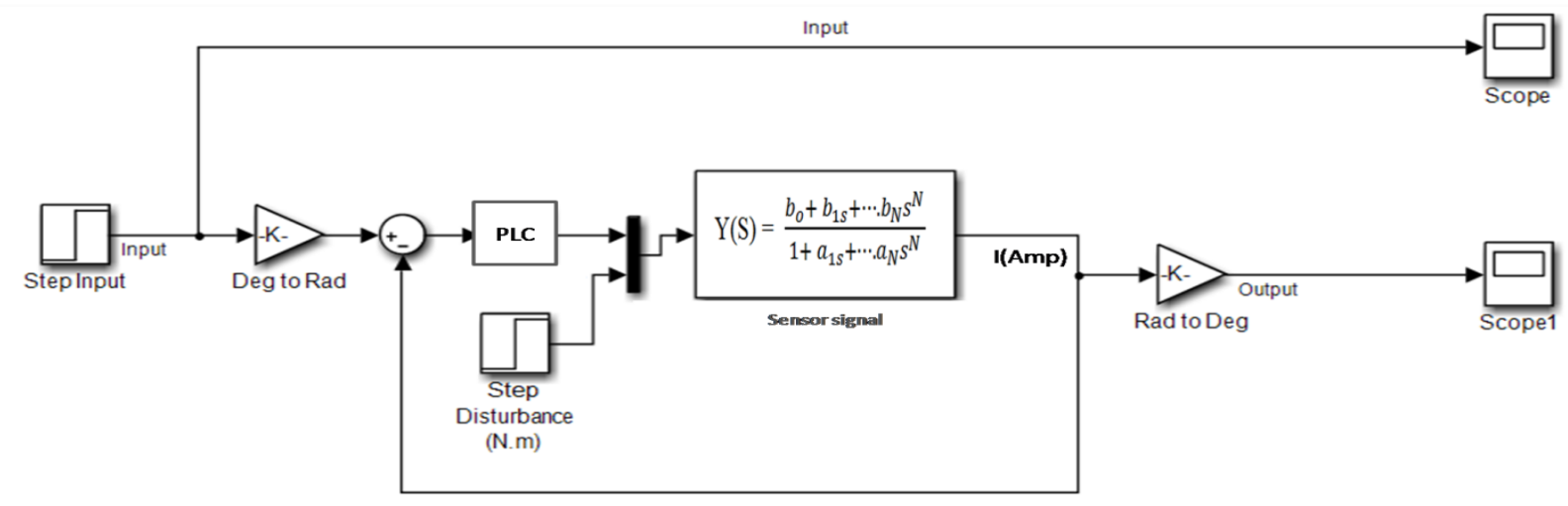

Figure 2: simulink model of the PLC controller 


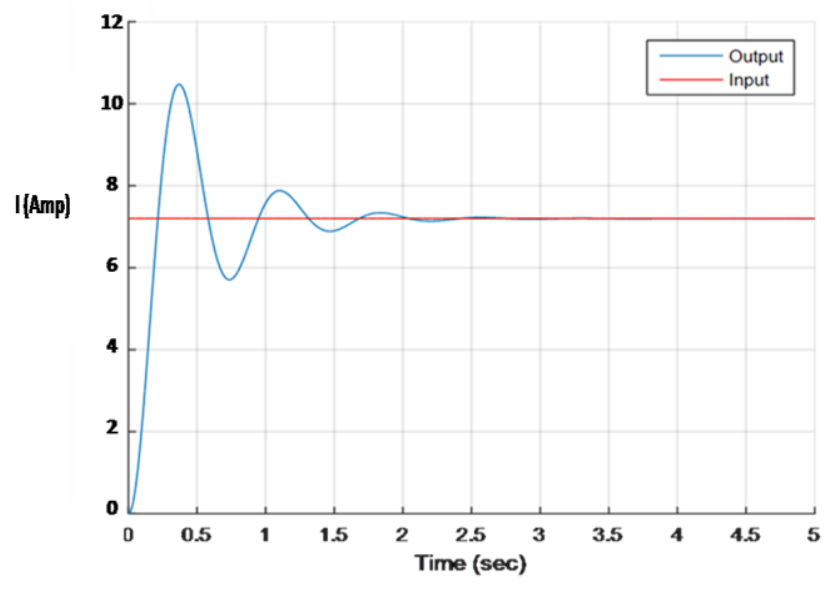

Figure 3: Performance of the PLC

\subsection{Improving the PLC with Artificial Neural Network}

To improve the PLC, artificial neural network was used. This network identified the PLC signal (current) through the neurons and as a nonlinear auto regressive model and training to generate an improve PLC model with neural network qualities.

\subsection{Nonlinear Auto Regressive Model}

This nonlinear current in Figure 3 is identified by the neural network as a nonlinear auto regressive model (NARM) as shown;

$y(k+d)=N(y(k), y(k-1), \ldots, y(k-n+1), u(k), u(k-1), \ldots \ldots$ $u(k-n+1))$
Where $u(k)$ is the PLC controlled current output, $N$ is the non linear transfer function from the sensor in equation $1, \mathrm{n}$ is the time series of interest, and $\mathrm{y}(\mathrm{k})$ is the system output which is identified by the ANN as NARM. This output is trained by the ANN using the back-propagation algorithm (see figure 4) and the training parameters in table 2 to develop a programmable neuro logic controller (PNLC) as shown in the structure;

${ }^{\wedge} y(k+d)=f(y(k), y(k-1), \ldots, y(k-n+1), u(k-1), \ldots, u(k-$ $m+1))+g(y(k), y(k-1), \ldots, y(k-n+1), u(k-1), \ldots, u(k-m$ $+1)) \cdot u(k)$

This PNLC model in equation 3, is used by the system to control other nonlinear signal from the load sensor and then feed to the variable frequency drive.

\section{Table 2: Neural Network Parameters}

\begin{tabular}{ll}
\hline Parameters & Values \\
\hline Train epoch values & 16 \\
The network hidden layers & 11 \\
Controller training segments & 30 \\
No. delayed reference input & 1 \\
Maximum feature output & 3.1 \\
Number of non-hidden layers & 2 \\
Maximum interval per sec & 2 \\
No. delayed output & 1 \\
No. delayed feature output & 2 \\
Minimum reference value & -0.7 \\
Maximum reference value & 0.7 \\
\hline
\end{tabular}

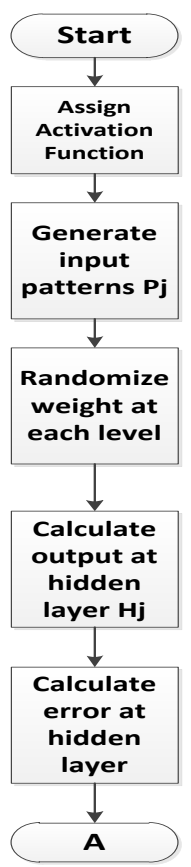

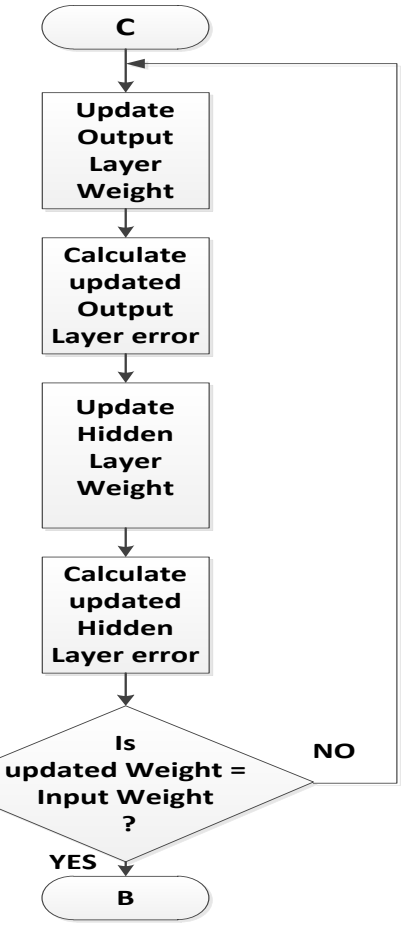

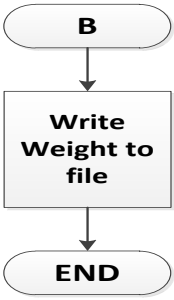

$\mathbf{e j}=\mathbf{P} \mathbf{j}-\mathbf{O} \mathbf{j}$

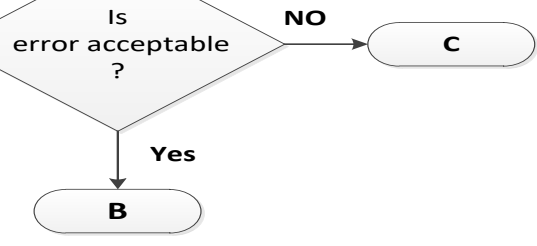

Figure 4: back-propagation algorithm flow chart 


\subsection{Variable Frequency Drive}

The VFD drive is a device employed for speed control as a result of load variation. According to [3] it is used to vary the speed of a system automatically with respect to the input load. The essence is to minimize energy consumption, reduce cost of energy, conserve energy, minimize maintenance cost, extend equipment life span and increase the system mean time to failure. The VFD is presented using the block diagram of Figure 5.

Table 3: VFD Specification

\begin{tabular}{ll}
\hline Parameters & Values \\
\hline Motor rating power & $4.07 \mathrm{KW}(0.5$ horse \\
rating & power $)$ \\
Current & $2.3 \mathrm{~A}$ \\
Voltage range $(\mathrm{AC})$ & $230 \mathrm{~V}$ \\
\hline
\end{tabular}

\subsection{Model of the 3-P Induction Motor}

The three phase induction motor employs three phase input voltage signals for the regulation of individual phase current, thus allowing control of the motor speed. The model presents electrical slip speed using the equation [14]:

$w_{\text {slip }}=w_{\text {syn }}-w_{\text {em }}$

Where $W_{e m}$ is the electrical speed $W_{\text {slip }}$ is the slip speed and $W_{\text {syn }}$ is synchronous speed of the motor respectively.

To calculate the rotor electrical speed with respect to the three rotational axes, the model employs the difference between the stator speed and slip speed as shown in the structure [14]:

$w_{d N}=w_{d n}-W_{\text {slip }}$

Where $w d_{N}$ is the given rotor axes for each phase, $w d_{n}$ is the stator axis for each phase.

To develop the model of the 3-phase induction motor the torque-speed relationship, this is given by relating each $\mathrm{n}$ phase characteristics with the slip speed in equation (4) as:

$$
T=\frac{\mathrm{nPR}_{2}}{w_{\text {slip }}} \frac{\mathrm{Vrms}^{2}}{\left(\mathrm{R}_{1}+\mathrm{R}_{2}+\frac{1-\mathrm{S}}{\mathrm{S}} \mathrm{R}_{2}\right)^{2}+\left(\mathrm{X}_{1}+\mathrm{X}_{2}\right)^{2}}
$$

where: , $\mathrm{P}$ is the number of poles, $\mathrm{V}_{\text {rms }}$ is the lineneutral supply voltage for a star-configuration induction motor, and the line-to-line voltage for a delta-configuration induction motor, $\mathrm{n}$ is the number of phases which is $3, n$ is the number of phase, $s$ is the stator slip, $R_{1}$ is the stator resistance; $R_{2}$ is the rotor resistance with respect to the stator; $X_{1}$ is the stator inductance; $X_{2}$ is the rotor inductance with respect to the stator; $\mathrm{V}$ and $\mathrm{I}$ are the sinusoidal supply voltage and current phasor. According to [11], in a case where controlled torque motor is used, the speed of the motor is used with relation to the torque to determined the power $(\mathrm{kw})$ as:

$$
P=(\text { Toque } \times \text { Speed }) / 52527
$$

\section{SYSTEM IMPLEMENTATION}

The system is implemented using the mathematical models designed in the previous sections, Control System Toolbox, Neural Network Toolbox and Simulink. The implementation result in Figure 6 shows the Simulink model of the improved PLC controller (see equation 3). The model was developed approximating the nonlinear output current function of the PLC through back-propagation using with artificial neural network to develop the PNLC.

The PNLC as shown in Figure 6 was used to control the nonlinear current from the load sensor with the aim of achieving better current output controlled response than the traditional PLC performance in Figure 3. The acquired control current signal which is an equivalent controlled torque signal is feed to the VFD to control the 3-PIM as shown in the Figure 7.

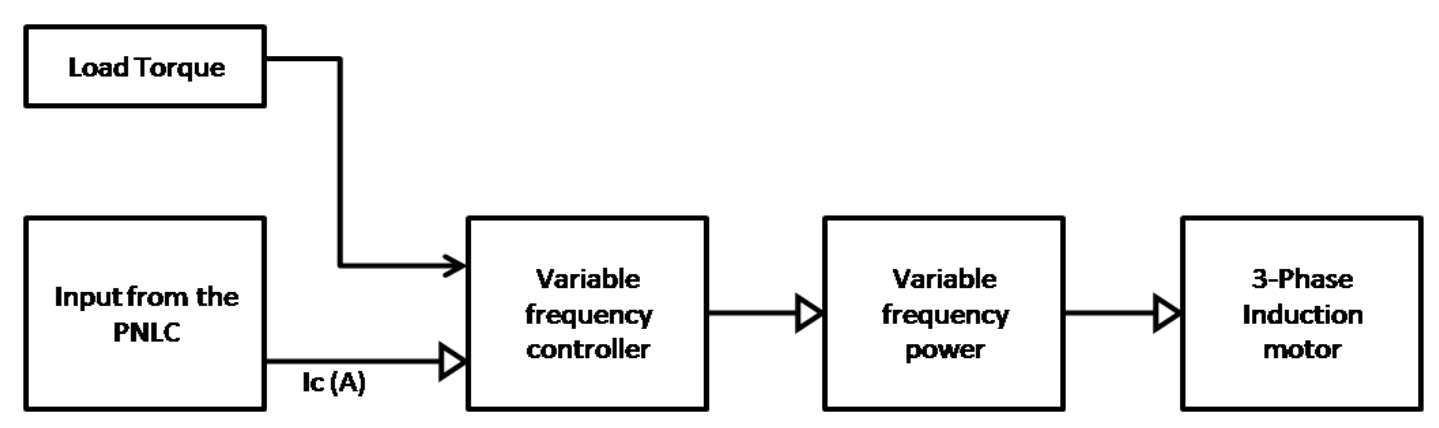

Figure 5: block diagram of the VFD 


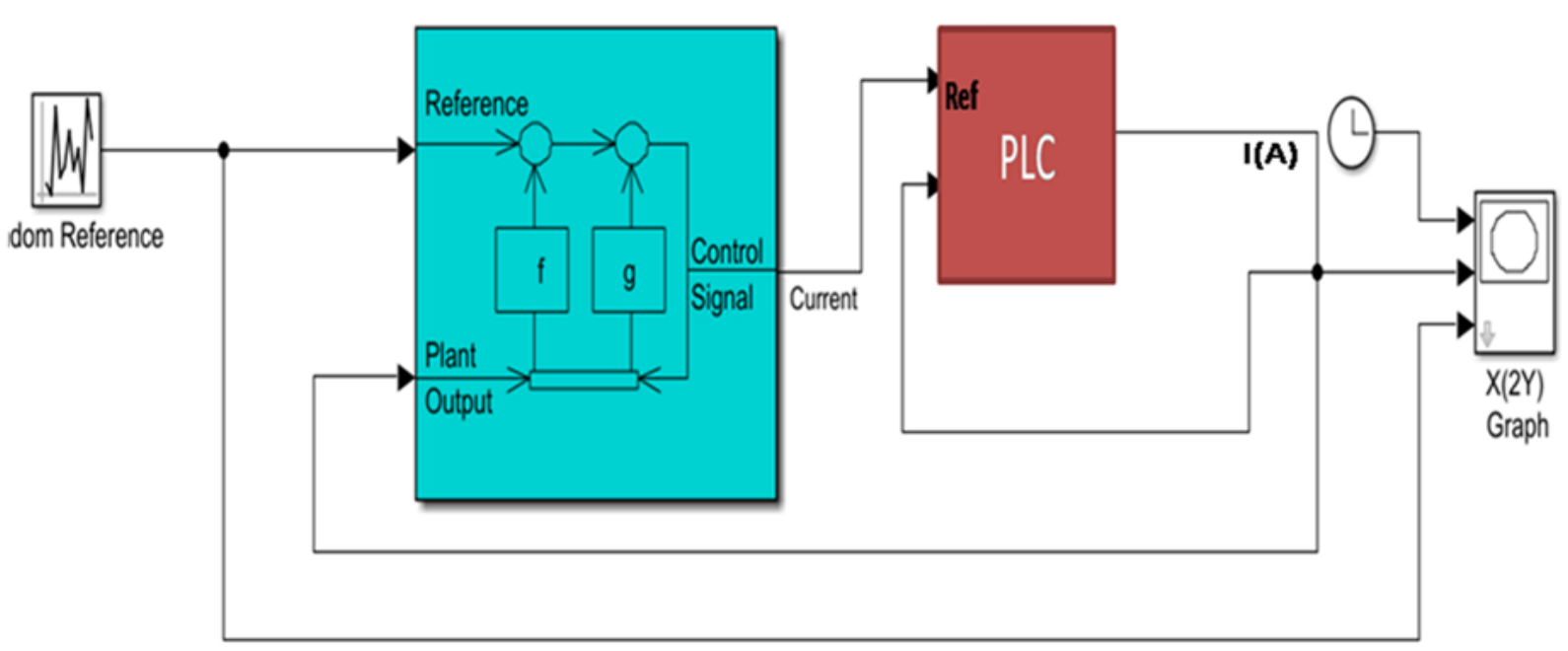

Figure 6: simulink model of the PNLC

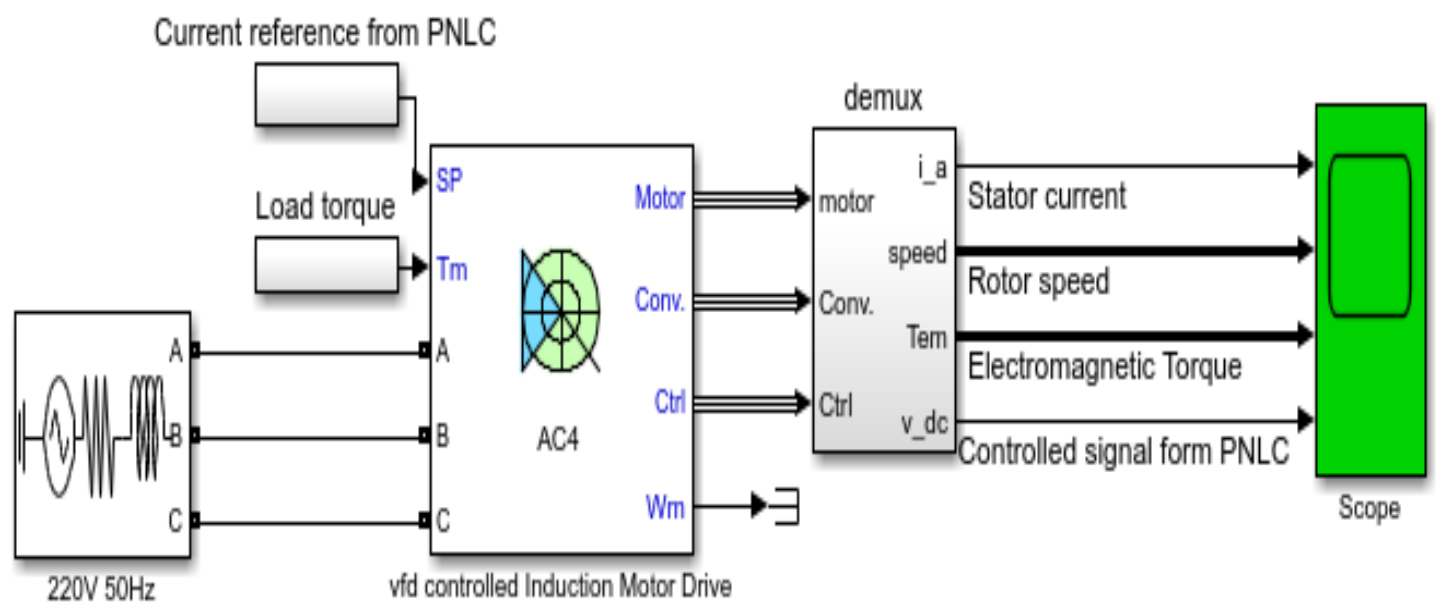

Figure 7: simulink model of the VFD controlled 3-PIM

From the implemented model in Figure 7, the VFD was feed with the controlled signal (current) from the PLNC with its equivalent controlled torque to control the 3PIM, from the scope the rotor speed and torque characteristics and power used was measured and the results discussed in the next section.

\section{RESULTS AND DISCUSSIONS}

The implemented models (PNLC and VFD controlled motor) were simulated using the simulation parameters in Table 1, Table 2 and Table 3; from the simulation result obtainedfor the PNLC controller model, the step response of the PNLC are presented in figure 8 ; the resultrevealed that the hybrid controller performs a lot better with response time of $1.22 \mathrm{sec}$ compared to the traditional PLC step response time (2.25sec) in Figure 3; also overshoot have been eliminated and a better steady state rate have been achieved.
The result in Figure 8 shows the step response control performance of the PNLC to the nonlinear current identified with equation 1 . The result shows that the PNLC controlled perfectly the nonlinear current signal from the load cells with no overshoot and fast settling time (1.25s)

This controlled signal (current) is feed to the VFD for automation of the 3-PIM as shown in the result of the simulation of the simulink in Figure 7, the VFD now controls the speed of the motor by varying the frequency and voltage supplied from the three phase powersource to the motor. The power consumed by the motor during the process is determined using the power model which relates speed, torque and the maximum speed of the motor (5252rpm) as shown in the model of equation 7 and are recorded in the Table 4. 


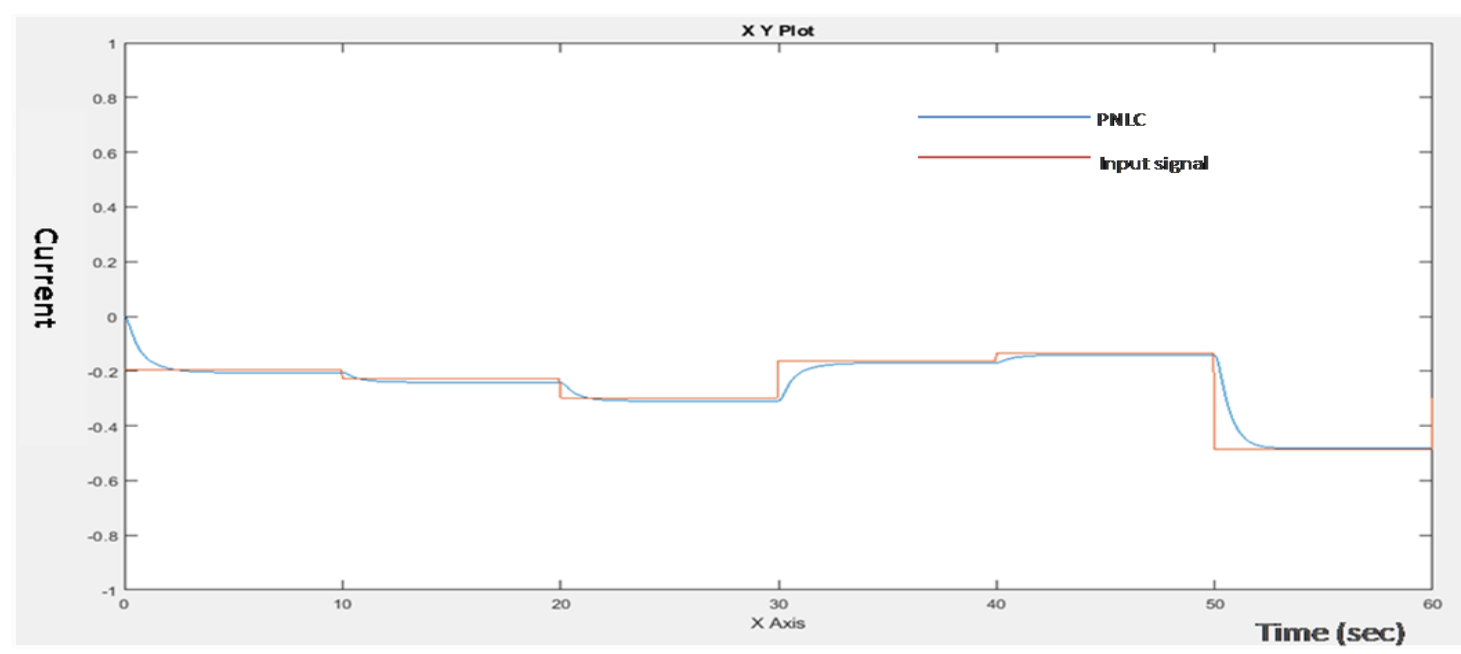

Figure 8: Step response of the PNLC

From the result of motor performance generated based on the model of equation (5), (6) and (7) respectively. The controlled torque 3-PIM was able to regulate speed and power proportionally. The result shows that a total of $13.16 \mathrm{~kW}$ of power has been consumed during the technical process. It was also observed that as the power increase, the speed of the motor also increases and vice versa. This power torque characteristics is analyzed as shown in Figure 9.

From the motor performance in Figure 9, the controlled torques were observed which are approximately the same rating $(11.17 \mathrm{Nm})$, however the power consumed was controlled with only $13.16 \mathrm{~kW}$ of power supplied. Also the equivalent speed response of the motor as a result of the variable power is presented in the analyzer.

From the result in Figure 10, the equivalent speed of the motor was analyzed and it was observed that within the processing time, the total speed measured of the motor by the analyzer is $6188 \mathrm{rpm}$.

\subsection{Rate of energy conservation}

To determine the rate of energy conservation achieved in the new system a comparative analysis was performed between the new system and a characterized system at the same condition. The results of the analysis is recorded side by side as shown in graphs of Figure 11 and Figure 12.

From the result presented in Figures 11 and 12 the performance of the new and characterized system have been presented considering power and speed. It was observed that in the new system, as the power decreases, the speed of the motor also decreases, however in the charcaterized system, the power is approximately with the same percentage errordue to the controlled performance of the conventional controller.

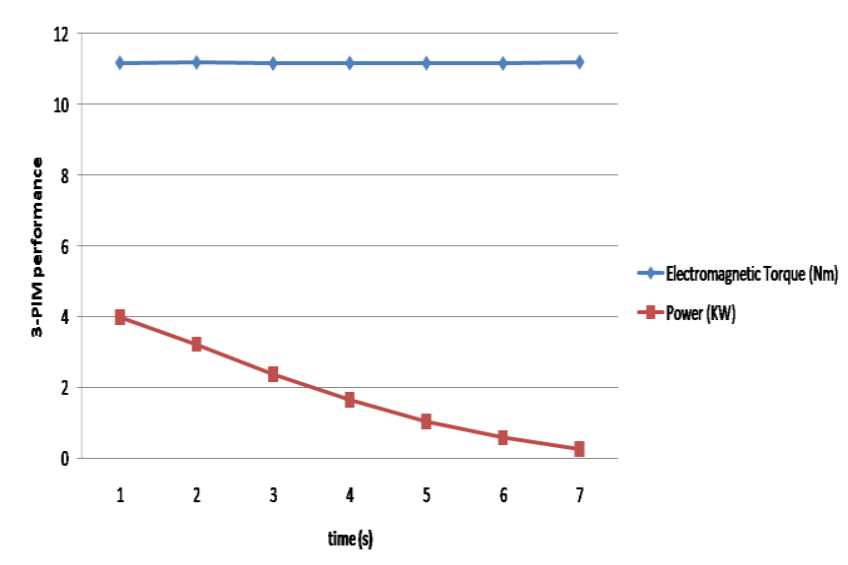

Figure 9: Torque and power performance of the new system

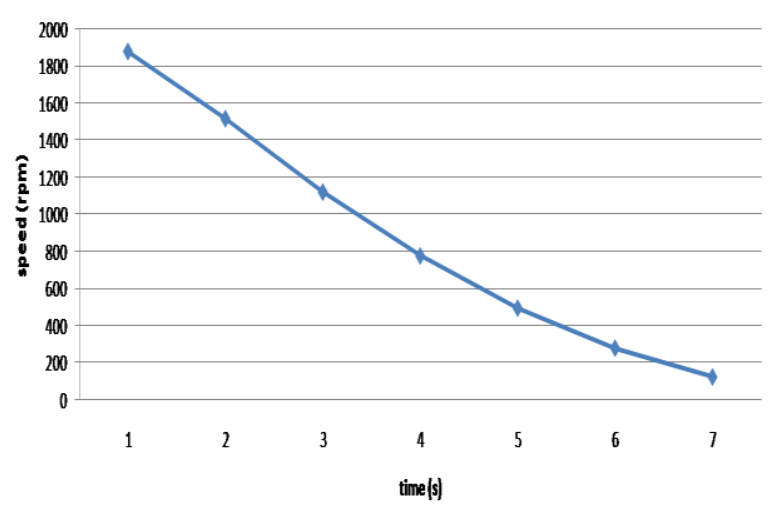

Figure 10: speed performance of the new system 


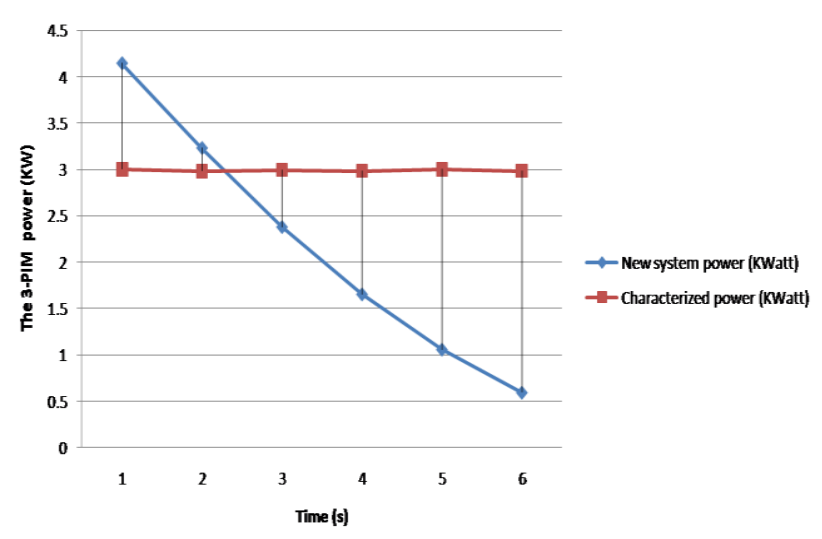

Figure 11: Comparative power result

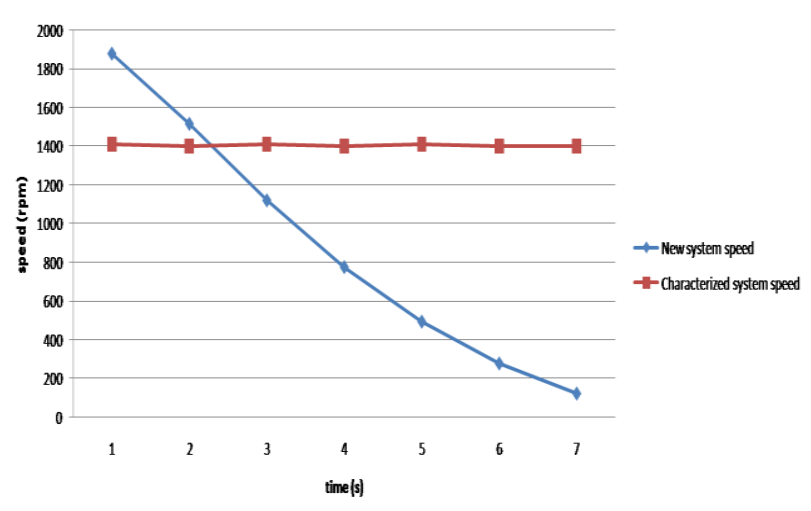

Figure 12: Comparative speed performance

The implication of this result shows that in the new system $37.07 \%$ of power was conserved, compared with the characterized system with $0 \%$ power conservation rate.This result is analyzed using the HMI oscillator in Figure 11.

From the result obtained in the figure 11; the power effect on the 3-PIM was analyzed to justify the performance of the new system, which shows how the consumption rate of energy reduced when the load reduced and the characterized on the other hand still consuming the same power rating throughout the operation time. Furthermore, this analyzesconsidered the speed of the motor, based on the same simulation platform. The result is shown in Figure 12.

From the comparative speed analysis performed, the total speed of the motor for the new system was $6188 \mathrm{rpm}$, while that of the characterized was 9833rpm respectively at the same time. The implication of the result shows that in the new system, only $62.93 \%$ of the speed used in the characterized was required. That means that the energy used to power the remaining $37.07 \%$ of the speed was a waste in the characterized system. The implication of this result shows that the new system will save the cost of $37.07 \%$ of the energy which was wasted in the characterized.

\section{CONTRIBUTION TO KNOWLEDGE}

Having completed this research paper, the following are the novel contribution

1. The traditional industrial PLC with step response $2.25 \mathrm{~s}$ settling time and some degree of overshoot has been improved using artificial neural network to develop a PNLC with step response time of $1.22 \mathrm{~s}$ and complete steady state output current response.

2. Complete system automation has been achieved using the PNLC and VFD on the 4.07kW 3-PIM with $37.07 \%$ energy conserved compared with the characterized with $20 \%$ energy conservation rate, when tested with the same input variables.

\section{CONCLUSION}

This paper has successfully optimized the control and automation performance of a 3-phase induction motor. This was done improving the control performance ofPLC using artificial neural network to develop a PNLC. This was used to control nonlinear current from the load sensor and feed to the VFD for control of the 3-PIM with respect to the load. This result obtained shows that a huge amount of useful energy was conserved when compared to the characterized system and also in a long run increase the life span of the industrial system at low maintenance and energy cost.

\section{REFERENCES}

[1] Bimal, K. B. "Recent Electronics and Motor Drive Recent Progress and Perspective" IEEE Transaction on Industrial Electronics, Vol. 56, No.2, February 2017.pp 581-587.

[2] Ammad, A. "Speed control, monitoring and protection of single phase induction motor"; Institute of Southern Punjab, Multan, 2015.

[3] Rao N.M., Vidya G., Prachi K and Pave D." PLC application for speed control of induction motor through VFD" International Research Journal of Engineering and Technology (IRJET), Vol 4, Issue 02, 2012.

[4] Ashfaq H. "Electric machines" by Dhanpat Rai publication co. (pvt) Ltd. Educational and Technical Publishers, 2002.

[5] Ariful I. A., Shamim, H. U. and Mohammad A. B. "Design and Implementation of a Low-cost MOSFET Based Chopper Drive DC Motor Speed 
Control" Journal of Science and Technology, Vol. 9 No. 2, 2017, pp. 6-9

[6] Dewangan, A.K. and Chakraborty, N. "PWM Based Automatic Closed Loop Speed Control of DC Motor" in International Journal of Engineering Trends and Technology, Vol. 3, 2012, pp. 110112.

[7] Afrasiabi, N and Yazdi, M.H. "DC Motor Control Using Chopper", Journal of Science, Engineering and Technology, 2012, Vol. 8 pp. 67-73.

[8] Inyiama H. C., and Agbaraji C. E. "Survey of Controller Design Methods for A Robot Manipulator In Harsh Environments; European Journal of Engineering and Technology, Vol.3 No.3, 2015.

[9] Okafor P.U., Eneh P. C., Arinze S.N., "Model Reference Adaptive Control (MRAC) Scheme For Eliminating Overshoot In DC Servomotor". International Journal of Advanced Research in IT and Engineering2017, Volume 6, Issue 3. Pp.1430.

[10] Mohan, N. "Advanced Electric Drives: Analysis, Control and Modeling Using Simulink". Minneapolis, MN: MNPERE, 2001.

[11] http://www.mathworks.com/help/ documentation

[12] Astrom, K. J., and Hagglund, T. "Advanced PID Control", International Society of Automation, Research Triangle Park, NC, 2005.

[13] Oraee H., Filizadeh S, "The impact of harmonic order on insulation aging in electric motors" $36^{\text {th }}$ University Power Engineering Conference, UPEC2001, UK, Sept. 2001

[14] Lyshevski S.E, "Electromechanical Systems, Electric Machines, and Applied Mechatronics", CRC, 1999. 